\title{
A snapshot of European neurosurgery December 2019 vs. March 2020: just before and during the Covid-19 pandemic
}

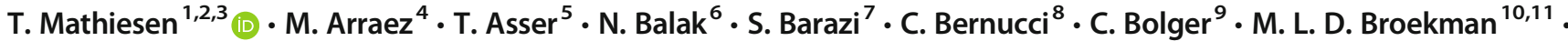

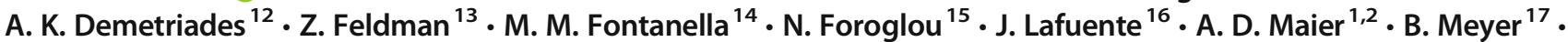 \\ M. Niemelä ${ }^{18}$ - P. H. Roche ${ }^{19}$ - F. Sala ${ }^{20}$ • N. Samprón ${ }^{21} \cdot$ U. Sandvik ${ }^{3,22} \cdot$ K. Schaller ${ }^{23} \cdot$ C. Thome ${ }^{24} \cdot$ M. Thys $^{25}$.

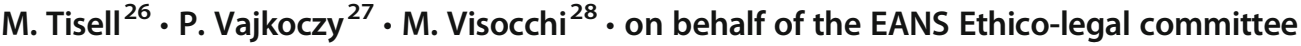

Received: 8 June 2020 / Accepted: 30 June 2020 / Published online: 8 July 2020

(C) Springer-Verlag GmbH Austria, part of Springer Nature 2020

\begin{abstract}
Background Severe acute respiratory syndrome coronavirus 2 (SARS-CoV-2 or Covid-19), which began as an epidemic in China and spread globally as a pandemic, has necessitated resource management to meet emergency needs of Covid-19 patients and other emergent cases. We have conducted a survey to analyze caseload and measures to adapt indications for a perception of crisis.

Methods We constructed a questionnaire to survey a snapshot of neurosurgical activity, resources, and indications during 1 week with usual activity in December 2019 and 1 week during SARS-CoV-2 pandemic in March 2020. The questionnaire was sent to 34 neurosurgical departments in Europe; 25 departments returned responses within 5 days.

Results We found unexpectedly large differences in resources and indications already before the pandemic. Differences were also large in how much practice and resources changed during the pandemic. Neurosurgical beds and neuro-intensive care beds were significantly decreased from December 2019 to March 2020. The utilization of resources decreased via less demand for care of brain injuries and subarachnoid hemorrhage, postponing surgery and changed surgical indications as a method of rationing resources. Twenty departments $(80 \%)$ reduced activity extensively, and the same proportion stated that they were no longer able to provide care according to legitimate medical needs.

Conclusion Neurosurgical centers responded swiftly and effectively to a sudden decrease of neurosurgical capacity due to relocation of resources to pandemic care. The pandemic led to rationing of neurosurgical care in $80 \%$ of responding centers. We saw a relation between resources before the pandemic and ability to uphold neurosurgical services. The observation of extensive differences of available beds provided an opportunity to show how resources that had been restricted already under normal conditions translated to rationing of care that may not be acceptable to the public of seemingly affluent European countries.
\end{abstract}

Keywords Covid-19 $\cdot$ Europe $\cdot$ Healthcare management $\cdot$ Epidemic $\cdot$ Neurosurgery $\cdot$ Pandemic $\cdot$ SARS-CoV-2

This article is part of the Topical Collection on Neurosurgery general

Electronic supplementary material The online version of this article (https://doi.org/10.1007/s00701-020-04482-8) contains supplementary material, which is available to authorized users.

T. Mathiesen

Tiit.illimar.mathiesen@regionh.dk

Extended author information available on the last page of the article

\section{Introduction}

The severe acute respiratory syndrome coronavirus 2 (SARSCoV-2 or Covid-19) pandemic has forcibly affected healthcare in other subspecialties than the primarily involved: intensive care, infectious diseases, and general practice. Neurosurgery is influenced by the redistribution of medical resources to those acutely needing Covid-19 care and by the need to handle or prevent Covid-19 among neurosurgical patients and staff [1-5].

Several editorials, letters, and articles have given accounts of neurosurgery during the Covid-19 pandemic [1, 4-9]. The 
immediate responses include diversion of ventilators and intensive care resources to prepare management of Covid-19 patients with subsequent decrease in neurosurgical resources and extensive postponing of elective patients. Patients are triaged and prioritized to manage all patients' medical needs. During the pandemic, regular neurosurgical emergences still occur [4] and the needs of these patients must be coordinated with the extraordinary demands of healthcare for Covid-19 patients. With terminology such as "triage" and "prioritization," the public and professionals communicate that all medical needs can be met, although extreme adjustment and measures are necessary (Mathiesen T., submitted). Still, rationing can also become necessary. Practically, rationing can be initiated horizontally by limiting resources for urgent neurosurgery and vertically by change of indications for surgery or intensive care.

We have undertaken a questionnaire survey of 25 neurosurgical departments in Europe to identify differences and similarities of resources, caseload, and indications during 1 week of presumed regular practice in December 2019 compared with a week in March 2020, when practice was expected to be heavily influenced by the pandemic. The aim was to survey differences and similarities in how neurosurgical care was affected by the Covid-19 pandemic.

\section{Methods}

A brief questionnaire (Appendix 1) was constructed to survey catchment areas, neurosurgical bed availability, caseload, need of rationing/prioritization, and indications for treatment during 1 week in December 2019 (Monday, December 9, 2019, to Sunday, December 15, 2019) compared with 1 week in March 2020 (Monday, March 23, 2020, to Sunday, March 29, 2020). The questionnaire was sent to one local investigator identified either as a board member of the European Association of Neurosurgical Societies (EANS) or a member of the EANS Ethico-legal committee or chosen from personal networks to represent countries not represented in the two previous bodies, between March 31 and April 3, 2020. The intention was to cover different European regions via member countries of EANS with one department in every country and to obtain better coverage of Italy and Spain, two countries that were initially most severely struck by Covid- 19 . Each local investigator was asked to select five qualified neurosurgeons including themselves and respond to the questionnaires. The local investigators were asked to either return all five forms or to synthesize the center's five responses and submit the aggregated result before April 7, 2020. The forms were collected, and results were compiled centrally by the first author (TIM). Unclear data was clarified via telephone contact with the local investigators. Numeric data for beds and treated patients were normalized to $1,000,000$ catchment area population for comparability. Data on Covid-19 caseload in different countries was assessed from reported cumulative deaths from Covid-19 and diagnosed in May 2020 cases of Covid-19 per million population via the Worldometers website [10]. Statistical analyses were comprised of MannWhitney $U$ test, sign test, Fisher exact test, and $t$ test as specified in results.

\section{Results}

Requests to fill out questionnaires were sent to 34 centers in 26 countries, and responses were obtained from 25 centers in 18 countries (Table 1 ). The results comprise mean survey responses from five responders at each site (totally 125 responders). Quantitative responses varied $<10 \%$ from individual responders in each center. Responses on the management of different hypothetical patients showed complete intracenter agreement in 20 centers $(80 \%)$ and differed for one assessment in $1 / 5$ responders in the residual four centers. Nineteen centers responded with separate responses from the five surgeons, while six centers replied with one unified response collated by the local investigator. Subjective assessment of whether medical needs were met showed intracenter agreement in 20 centers $(80 \%)$, while 1 or 2 of the five responders differed from the majority in the remaining five centers $(20 \%)$.

\section{Catchment areas and subjective evaluation of therapeutic challenges}

The responding centers were regional or national tertiary university referral centers $(n=23,92 \%)$ or regional neurosurgical hospitals $(n=2,8 \%)$. The catchment areas varied from 450,000 to $5,000,000$ persons. Four departments (16\%) had smaller catchment areas than 800.000 (in Estonia, Spain, Turkey, and Belgium), eleven departments (40\%) had catchment areas between 800,000 and 1,200,000, and ten departments (44\%) had larger catchment areas than 1,500,000 (two in Sweden, England, Scotland, Finland, Denmark, two in Germany, Netherlands, and Ireland).

Twenty-four of the 25 responders $(96 \%)$ graded their situation at the end of March as either "stable, but with concerns" $(n=14)$, difficult with extreme measures $(n=8)$, or "desperate" $(n=2)$. One center did not respond to this question.

\section{Neurosurgical beds}

The number of neurosurgical beds (regular + intermediate care) varied from 3 to $84 / 1,000,000$ inhabitants and NeuroICU beds from 2 to $42 / 1,000,000$ inhabitants in December 2019. Eight departments had fewer than 25 beds per $1,000,000$, and 6 departments had 5 or fewer neuro-ICU beds 
Table 1 Centers, catchment area, assessment whether all medical needs can be met, limitation of treatment indications between December and March, same, increased or decreased activity, and number of regular neurosurgical and intensive care beds. The national burden of Covid-19 is outlined below, as is the subjective evaluation of the local Covid-19 situation: stable/difficult, extreme, or desperate

\begin{tabular}{|c|c|c|c|c|c|c|c|c|c|c|c|}
\hline \multirow[t]{2}{*}{ Center } & \multirow[t]{2}{*}{$\begin{array}{l}\text { Catchment area(in } \\
\text { millions) }\end{array}$} & \multicolumn{2}{|c|}{$\begin{array}{l}\text { Care for all needs } \\
(\text { yes }=y, \text { no }=n)\end{array}$} & \multirow[t]{2}{*}{$\begin{array}{l}\text { Indications(same or limitedin } \\
\text { March) }\end{array}$} & \multicolumn{3}{|c|}{$\begin{array}{l}\text { Activity } \\
\text { (craniotomies in } \\
\text { December vs. } \\
\text { March) }\end{array}$} & \multicolumn{2}{|c|}{$\begin{array}{l}\text { Regular and } \\
\text { intermediate beds } \\
\text { (beds/catchment } \\
\text { area in millions) }\end{array}$} & \multicolumn{2}{|c|}{$\begin{array}{l}\text { ICU beds } \\
\text { (beds/catchment } \\
\text { area in millions) }\end{array}$} \\
\hline & & December & March & & SAH & TBI & Tumor & December & March & December & March \\
\hline $1 \#$ & 1.0 & $\mathrm{y}$ & $\mathrm{n}$ & Same & $\downarrow$ & $\downarrow$ & $\downarrow$ & 63 & 36 & 20 & 11 \\
\hline $2 \#$ & 0.8 & $\mathrm{y}$ & $\mathrm{n}$ & Same & $\uparrow$ & $\downarrow$ & $\downarrow$ & 45 & 19 & \multicolumn{2}{|c|}{ Not available } \\
\hline $3 \#$ & 1.0 & $\mathrm{y}$ & $\mathrm{y}$ & Same & $\rightarrow$ & $\rightarrow$ & $\rightarrow$ & 40 & 40 & 12 & 12 \\
\hline $4 \#$ & $0.8^{\prime}$ & $\mathrm{y}$ & $\mathrm{n}$ & Same & $\rightarrow$ & $\downarrow$ & $\downarrow$ & 34 & 20 & 11 & 4 \\
\hline $5 * \#$ & 1.2 & $y$ & $n$ & Limited & $\downarrow$ & $\downarrow$ & $\downarrow$ & 28 & 7 & 7 & 0 \\
\hline $6 * \#$ & 1.0 & $y$ & $n$ & Limited & $\downarrow$ & $\downarrow$ & $\downarrow$ & 44 & 14 & 8 & 0 \\
\hline $7 * \#$ & 1.0 & $y$ & $n$ & Same & $\rightarrow$ & $\uparrow$ & $\downarrow$ & 66 & 56 & 18 & 6 \\
\hline 8 *\#\# & 1.0 & $y$ & $n$ & Limited & $\rightarrow$ & $\downarrow$ & $\downarrow$ & 40 & 10 & 12 & 3 \\
\hline $9 \#$ & 2.0 & $\mathrm{y}$ & $\mathrm{n}$ & Same & $\rightarrow$ & $\rightarrow$ & $\rightarrow$ & 15 & 10 & 4 & 4 \\
\hline $10 * \# \#$ & 5.0 & $y$ & $n$ & Limited & $\downarrow$ & $\downarrow$ & $\downarrow$ & 22 & 12 & 6 & 0.6 \\
\hline $11 * \#$ & 1.5 & $y$ & $n$ & Limited & $\downarrow$ & $\downarrow$ & $\downarrow$ & 33 & 21 & 4 & 1 \\
\hline $12 * \# \#$ & 0.95 & $y$ & $n$ & Limited & $\downarrow$ & $\downarrow$ & $\downarrow$ & 31 & 8 & 8 & 0 \\
\hline $13 * \# \#$ & 0.45 & $y$ & $n$ & Limited & $\downarrow$ & $\downarrow$ & $\downarrow$ & 27 & 2 & 9 & 0.2 \\
\hline $14 * \# \#$ & 2.4 & $y$ & $y$ & Same & $\rightarrow$ & $\downarrow$ & $\downarrow$ & 29 & 19 & 6 & 2 \\
\hline $15 \# \#$ & 1.0 & $\mathrm{y}$ & $\mathrm{n}$ & Limited & $\downarrow$ & $\downarrow$ & $\downarrow$ & 30 & 8 & 1 & 0.2 \\
\hline $16 \#$ & 2.0 & $\mathrm{n}$ & $\mathrm{n}$ & Limited & $\rightarrow$ & $\downarrow$ & $\downarrow$ & 3 & 3 & 4 & 4 \\
\hline $17 \#$ & 1.9 & $\mathrm{n}$ & $\mathrm{n}$ & Limited & $\uparrow$ & $\rightarrow$ & $\rightarrow$ & 13 & 9 & 3 & 3 \\
\hline $18 \# \#$ & 0.5 & $\mathrm{y}$ & $\mathrm{y}$ & Limited & $\downarrow$ & $\downarrow$ & $\downarrow$ & 70 & 28 & 14 & 4 \\
\hline $19 \#$ & 2.2 & $\mathrm{y}$ & $\mathrm{y}$ & Same & $\rightarrow$ & $\downarrow$ & $\downarrow$ & 22 & 22 & 6 & 5 \\
\hline $20 \#$ & 2.5 & $\mathrm{y}$ & $\mathrm{n}$ & Same & $\uparrow$ & $\rightarrow$ & $\uparrow$ & 16 & 12 & 6 & 8 \\
\hline $21 * \#$ & 0.45 & $y$ & $n$ & Same & $\uparrow$ & $\rightarrow$ & $\uparrow$ & 84 & 84 & 42 & 21 \\
\hline $22 * \#$ & 4.5 & $y$ & $n$ & Limited & $\downarrow$ & $\downarrow$ & $\downarrow$ & 14 & 13 & 2 & 2 \\
\hline $23 \# \#$ & 0.5 & $\mathrm{y}$ & $\mathrm{n}$ & Limited & $\downarrow$ & $\downarrow$ & $\downarrow$ & 60 & 20 & 16 & 4 \\
\hline 24\#\# & 4.0 & $\mathrm{y}$ & $\mathrm{n}$ & Same & $\rightarrow$ & $\rightarrow$ & $\uparrow$ & 18 & 18 & 5 & 5 \\
\hline $25 \#$ & 3.7 & $\mathrm{y}$ & $\mathrm{y}$ & Same & $\downarrow$ & $\rightarrow$ & $\downarrow$ & 23 & 16 & 8 & 7 \\
\hline
\end{tabular}

$*=>500$ deaths by Covid-19 per million or $>4000$ Covid-19 diagnoses per million

\# = stable, manage with some measures; \#\# = extreme situation, manage with difficulties; \#\#\# = desperate situation

per 1,000,000 inhabitants (England, Netherlands, two in Sweden, Ireland, Germany).

The number of neurosurgical beds and neuro-ICU beds was lower in March in 18/25 (72\%) and 16/25 (64\%) centers, respectively ( $p<0.01$, sign test). The median/mean numbers of neurosurgical beds decreased from $30 / 35$ to $19 / 20$, while neuro-ICU beds decreased from $7.5 / 10$ to $4 / 3.8$ beds per $1,000,000$ inhabitants.

We obtained a proxy parameter to estimate the Covid-19 caseload from reported cumulative Covid-19 diagnoses and deaths per million on May 19, 2020, that might have influenced neurosurgical care during the pandemic. There was a wide range of infected (minimum: 152 (Finland)-maximum: 5950 (Spain)) and deaths (minimum: 16 (Greece)-maximum:
786 (Belgium)) per million population. Four countries (Spain, UK, Italy, Ireland) reported either $>500$ deaths or $>4000$ diagnosed/million.

\section{Neurosurgical activity in December 2019 vs. March 2020 (Table 1)}

All centers reported comparable surgical activity/million inhabitants before the pandemic (December 2019): median 2.0 subarachnoid hemorrhage (SAH) patients in the ICU (75th percentile 2-8), median 2.5 SAH patients in the ICU (75th percentile 1-6), and median 5.0 elective craniotomies for brain tumors/week (75th percentile 1-6). 
Most centers treated fewer ICU-treated SAH patients in March 2020 during the pandemic than December 2019 before the pandemic $(z=2.3, p<0.05$, sign test). Thirteen of the responding centers $(52 \%)$ reported a decrease, while numbers were equal in eight centers $(32 \%)$ and higher in four. The mean numbers were 2.7 (range $0-16$ ) vs. 1.8 (range 0-8) SAH patients/1,000,000 catchment population in December 2019 and March 2020, respectively.

The numbers of ICU-treated patients with traumatic brain injury (TBI) were lower in March 2020 than December 2019 $(z=3.6, p<0.001$, sign test). Seven centers $(28 \%)$ reported an equal or increased number, while 18 centers $(72 \%)$ reported a decrease. The mean numbers were 3.6 (range 0-10) vs. 1.2 (range 0-8) TBI patients/1,000,000 catchment population in December 2019 and March 2020, respectively.

Most responding centers reported fewer elective craniotomies for brain tumors during the surveyed week in March 2020 than December $2019(z=3.3, p<0.001$, sign test). Five centers (20\%) reported an equal or increased number of elective craniotomies, while 20 (80\%) reported decreased activity. Six of the centers with decreased activity did not perform any elective craniotomies during the surveyed week of March. The mean number of elective craniotomies was 5.4 (range 1.5-10) vs. 2.3 (range 010)/1,000,000 catchment population in December and March, respectively.

\section{Attitudes toward medical need and available resources}

\section{Patients with legitimate medical needs}

Eighteen centers (72\%) reported that all patients with legitimate needs got cared for in December, but not in March (mean 39.4 neurosurgical +12.5 neuro-ICU beds/million catchment area in December, 21.3 + 4.4 in March). Five centers (in Finland, Israel, Spain, one in Germany and Switzerland) reported that all patients with legitimate needs received care at both time points (40.2 neurosurgical +9.5 neuro-ICU beds/million catchment area in December, $27.2+5.8$ in March), while two centers $(8+3.5$ beds in December, $6.0+3.5$ in March) stated that some patients were left without legitimate care at both time points.

\section{Demand for healthcare}

Responders from twelve centers (48\%) reported a consensus that demand for medical services will always be higher than the supply at either time point. Nine centers $(36 \%)$ reported that the demand was higher than the supply in March, but not in December. Only four centers (16\%) reported that the demand was not higher than supply at either time point (in Finland, Switzerland, one in Germany, Israel).

\section{Prioritization}

Prioritization was an issue that was discussed already in December 2019 in 15 centers. Twelve centers (48\%) also reported to have a system for prioritization at that time, while seven $(28 \%)$ reported to have initiated discussions and nine (36\%) implemented a system in March 2020. Prioritization was neither discussed nor systematized in two centers (8\%) (in Israel and Spain).

\section{Indications and waiting list for seven hypothetical patients (Figs. 1 and 2)}

Previously healthy 75-year-old patient with mild symptoms, surgically accessible glioblastoma (GBM; Figs. 1 and 2a)

All centers would operate the GBM patient in December 2019. The waitlist for the GBM patient was reported as 7 days or less in 15 centers $(60 \%)$ with a mean of 35.7 neurosurgical intermediate and general care beds/1,000,000 catchment area and 10-18 days in ten centers $(40 \%)$ with a mean of 34.4 beds/catchment area.

Nineteen/25 centers $(76 \%)$ would also operate the patient in March 2020, four (16\%) with a doubled time to surgery (one center centralized elective neurosurgery to one regional hospital), and one with more rapid access. Six centers $(24 \%)$ would not operate this patient (Turkey, Ireland, Scotland, England, Greece, Sweden). The mean number of beds was higher in the 19 (76\%) former than six latter centers (55/million in December 2019 and 16 in March 2020) vs. the six latter (29 and 14, respectively; the difference in March 2020 was, however, not statistically significant ( $p=0.46$, Mann-Whitney $U$ test)). Ten of eighteen decreased their number of beds $<30 \%$ in the former group vs. one of five in the latter $(p=0.08$, Fisher exact test).

Previously healthy 75-year-old patient with mild symptoms, surgically accessible convexity meningioma (Figs. 1 and 2b)

All centers would operate the meningioma patient in December 2019, ten (40\%) within 14 days, eight $(32 \%)$ between 2 and 6 weeks, and five (20\%) after 10 weeks (several months). Two centers $(8 \%)$ gave no estimate of waitlist. The waitlist for the meningioma patient was reported as 14 days or less in eight centers with a mean of 44.3 neurosurgical intermediate care and general care beds/1,000,000 catchment area, 36 weeks in eight centers with a mean of 36.9 beds/1,000,000 catchment area, and 


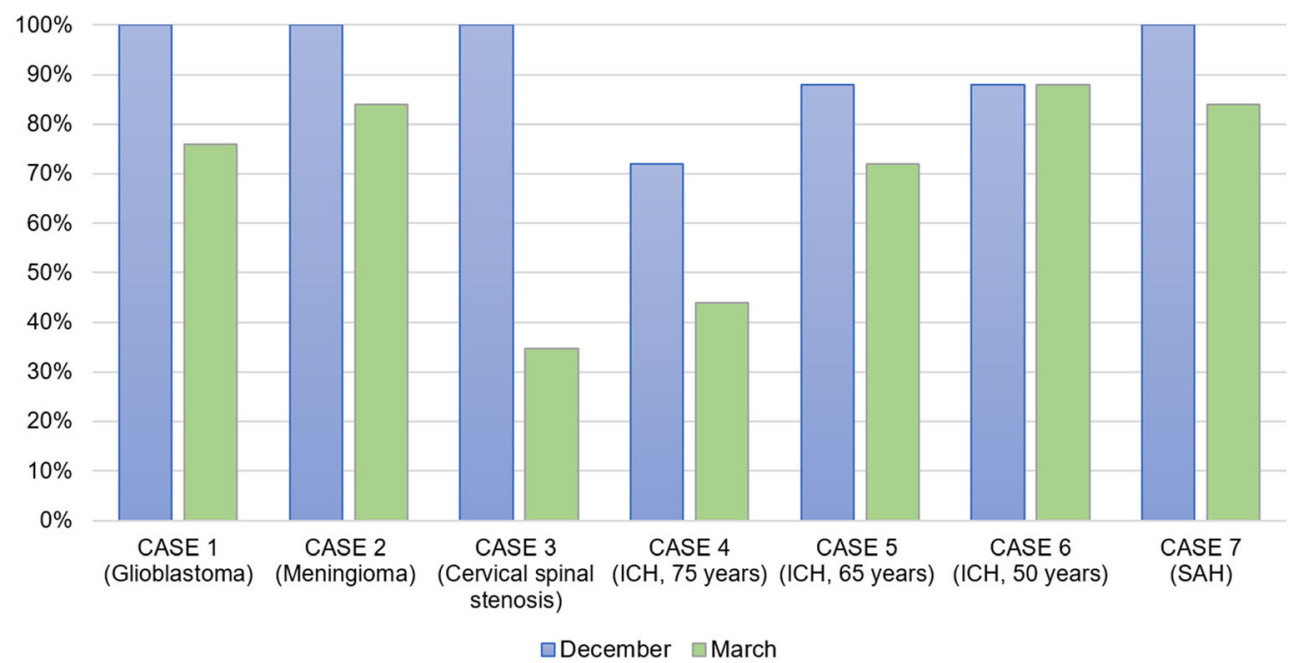

Fig. 1 Bar plot showing proportion of centers that would offer surgery to the hypothetical cases in December and March. The cases are further described in methods, questionnaire, and results. Briefly, cases 1-3 reflect elective patients with surgically accessible diseases: a 75-year-old patient with glioblastoma, a 75-year-old patient with a convexity meningioma,

and a 60 -year-old patient with symptomatic cervical spinal stenosis. Cases 4-6 comprise patients with surgically accessible $60 \mathrm{cc}$ lobar intracerebral hematomas; the patients are 75,65 , and 50 years old. Patient 7 has a severe subarachnoid hemorrhage with Hunt-Hess grade 4 and in need of external ventricular drainage

$8-20$ weeks in five centers with a mean of 19.6 beds $/ 1,000,000$ catchment area.

Ten centers $(40 \%)$ would operate the patient in March 2020 within 4-42 days; the waiting list would be increased by 1-4 weeks in four centers and unchanged in six. Four centers $(16 \%)$ would not offer surgery to this patient, which may reflect "not during the pandemic" (with previous waiting list of 2, 4, and $>8$ weeks). Eleven centers $(44 \%)$ would postpone surgery until "after corona," which was projected as 10-24 weeks.

\section{Previously healthy 60-year-old patient with cervical spinal stenosis and moderately progressive mild myelopathy (Figs. 1 and 2c)}

All 23 applicable (two centers, Israel and Denmark, subspecialized to not perform spinal surgery) centers would operate the patient in December 2019, four within 14 days, fourteen between 2 and 6 weeks, and three after 12 weeks. Two centers gave no estimate of waitlist. The waitlist for the spinal stenosis patient was reported as 4 weeks or less in 15 centers with a mean of 46.7 neurosurgical intermediate care and general care beds/1,000,000 catchment area and more than 6 weeks in seven centers with a mean of 25.7 beds $/ 1,000,000$ catchment area.

Seven centers would operate the patient in March 2020 with an unchanged waitlist of 7-90 days; two would increase the waitlist from 1 and 2 weeks to 2 and 3 weeks, respectively; nine would postpone surgery until "after corona," which was projected as 10-24 weeks; five stated they would not operate the patient, which may reflect "not during the pandemic" (Scotland, England, Ireland, Turkey, Greece).

Previously healthy 75 -year-old patient with hemiparesis, GCS $11,60 \mathrm{cc}$, surgically accessible lobar intracerebral hematoma (ICH; Fig. 1)

Eleven centers (44\%) would operate the lobar ICH in a 75 year-old patient in both December 2019 and March 2020; seven centers $(28 \%)$ would offer surgery in December 2019 but not March 2020 (two in Italy, two in Spain, Greece, Switzerland, Ireland); seven centers (28\%) would neither operate in December 2019 nor March 2020 (Austria, Germany, Scotland, England, Finland, two in Sweden).

Of the latter seven centers, six had access to 6.0 or fewer neuro-ICU beds $/ 1,000,000$ catchment areas while twelve of $18 / 1,000,000$ ( $p=0.02$; Fisher exact test).

The centers that would operate in December 2019 but not in March 2020 initially had 7.0 neuro-ICU beds $/ 1,000,000$ catchment areas which decreased by $87 \%$ to 0.9 per $1,000,000$, while the eleven centers that would operate at both times had access to 13.5 neuro-ICU beds $/ 1,000,000$ that decreased by $50 \%$ to 6.7 per 1,000,000 (the numbers of ICU beds were significantly lower in the centers that would not treat, than those who would treat in March $2020(p=0.013$; Mann-Whitney $U$ test), but not in December ( $p=0.46$; MannWhitney $U$ test).

\section{Previously healthy 65 -year-old patient with hemiparesis, GCS 11,60 cc, surgically accessible lobar ICH (Fig. 1)}

Eighteen centers $(72 \%)$ would operate the lobar ICH in a 65 year-old patient in both December 2019 and March 2020; four centers $(16 \%)$ would offer surgery in December but not in March (one in Italy, Greece, one in Sweden, Ireland); three 
Fig. 2 a-c Expected time to surgery in December and March for the elective patients $1-3$
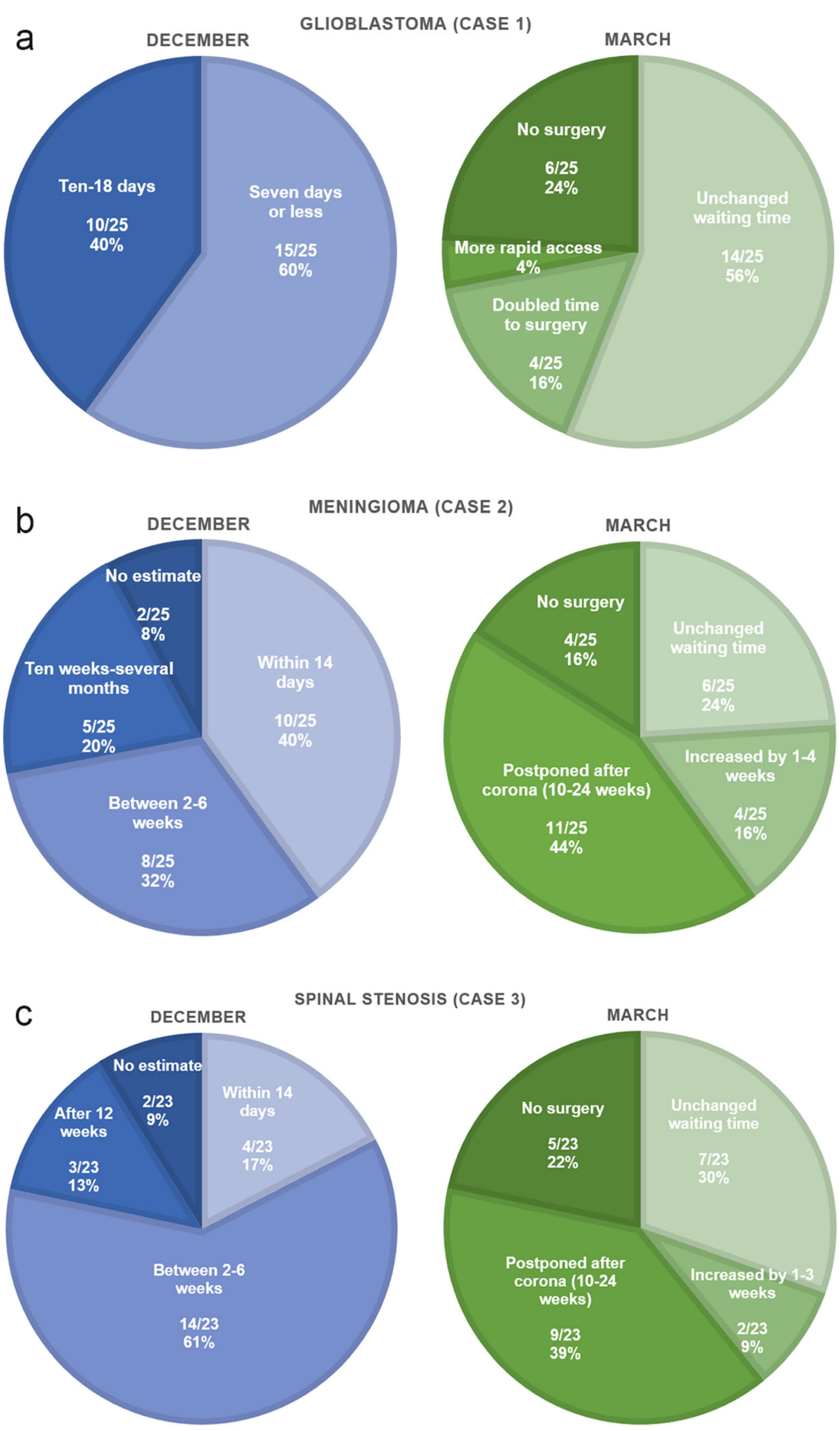
centers (12\%) would neither operate in December 2019 nor March 2020 (Germany, Scotland, England).

Previously healthy 50-year-old patient with hemiparesis, GCS 11,60 cc, surgically accessible lobar ICH (Fig. 1)

Twenty-two (88\%) centers would operate the lobar ICH in a 50-year-old patient in both December 2019 and March 2020; three centers (12\%) would neither operate in December 2019 nor March 2020 (Germany, Scotland, England). These three centers had six or fewer neuro-ICU beds/1.000.000 which was significantly less than available in the centers that would operate the patient ( $p=0.04$; Fisher exact test).

\section{Previously healthy 50-year-old patient with subarachnoid hemorrhage (SAH), Hunt and Hess grade 4 (Fig. 1)}

Twenty-one centers (84\%) would admit the SAH patient to the ICU and place an external ventricular drain (EVD) in December and March; four centers (16\%) would admit in December 2019 but not in March 2020 (one in Spain, Scotland, England, Ireland). These centers had 0.95 (range $0.2-2$ ) neuro-ICU beds $/ 1,000,000$, while the centers that would admit the patient had 5.7 (range $0-21$ ). The difference was not statistically significant $(p=0.09 ; t$ test).

\section{Changes in resources and activity between December 2019 and March 2020}

Thirteen centers (52\%) treated an equal number of SAH patients during the weeks in December 2019 and March 2020. Their neuro-ICU capacity had decreased with a mean of $50 \%$ compared with eleven centers (44\%) that treated fewer SAH patients, with a capacity decrease of $80 \%$. The proportional decrease was significantly higher in the latter group than the former $(p<0.05$, Mann-Whitney $U$ test).

Eight centers $(32 \%)$ treated an equal number of TBI patients during the weeks in December 2019 and March 2020. Their neuro-ICU capacity had decreased with a mean of $20 \%$ compared with seventeen centers (68\%) that treated fewer TBI patients, with a capacity decrease of $84 \%$. The proportional decrease was significantly higher in the latter group than the former ( $p<0.05$, Mann-Whitney $U$ test).

Seven centers (28\%) made an equal number of elective craniotomies during the weeks in December 2019 and March 2020. Their neurosurgical bed capacity had decreased with a mean of $20 \%$ compared with seventeen centers (68\%) that made fewer craniotomies, with a capacity decrease of $84 \%$. The proportional decrease was significantly higher in the latter group than the former $(p<0.05$, Mann-Whitney $U$ test).

Only one center $(40+12$ beds) reported similar indications and activity at both time points. Three centers reported similar indications and retained ability to provide care as needed but decreased activity in March (19-28 $+2-5$ beds). Four centers reported same indications and activity but an inability to meet all needs $(31(10-84)+9.5[1-4,6,8,11-22]$ beds $)$; four centers reported similar indications but decreased activity and inability to meet all needs $(33(19-56)+7[1,2,6,8,11-14]$ beds); and thirteen centers had limited their indications to treat patients.

\section{Discussion}

We obtained a snapshot of neurosurgical caseloads and indications during December 2019 and March 2020 and found major differences. The resources for neurosurgical patients decreased dramatically with fewer intermediate and regular neurosurgical beds in March 2020 than December 2019 in 19 of 25 responding centers; 16 centers reported fewer ICU beds. Correspondingly, admission and surgery of emergency cases as well as elective craniotomies decreased in most centers, while a minority of centers appeared to continue neurosurgical care almost unchanged. Nineteen centers reported that all patients with legitimate medical needs could not expect to have those needs met during the Covid-19 pandemic in the March 2020 week, and several centers gave examples of patients with neurosurgical emergencies that would not be treated.

\section{Survey of practice during pandemic as reflected by changes}

Preexisting differences in neurosurgical capacity and practice would fail to adequately reflect effects of the pandemic if only practices during the pandemic would be surveyed. Hence, we constructed a questionnaire that recorded practice and attitudes before and during the pandemic. The time points in December and March were chosen to reflect "regular practice" during a regular working week and practice affected by the Covid-19 pandemic in the vicinity of its European peak, respectively. We postulated that the supply of neurosurgical care would be in balance with demand and expectations in December 2019, but that supply would decrease and affect neurosurgical care during the pandemic. Several guidelines and recommendations have been recently published on how to manage the pandemic and possible shortage of resources [4, $11,15,22]$. The guidance comprises prioritization by postponing non-urgent cases, triaging of cases to use resources effectively and optimally meet individual medical needs, and, finally, rationing of cases: the process of selection of who will not be treated to optimally meet a medical need. We observed prioritization and rationing but with differences between centers. Optimization of care by reorganization was employed in some Italian and Spanish centers, where the responsibility of 
neurosurgical emergencies was concentrated to some centers while others took responsibility for regional elective care and still others shifted tasks to manage Covid-19 patients. Such task shifting [23] and concentration by sub-specialization are possible in healthcare systems that have several smaller centers, but not in countries like UK, Ireland, Denmark, Sweden, and Finland that already have fewer large regional centers with catchment areas often over 2,000,000 inhabitants. Moreover, the number of neurosurgical beds $/ 1,000,000$ was already low in the latter groups of countries, providing for only a small number of potential beds; these beds may have been used as efficiently as already under normal conditions. The mechanisms of demand and supply suggest that available resources affect how many and which patients are treated via local indications for admittance and surgery. Accordingly, regional centers in Europe with lowest number of beds responded that not all patients received therapy according to medical needs even before the pandemic in December 2019.

\section{Adjustment of services to decreased supply of resources via prioritization and rationing}

First, the demand for neurosurgery appears to have decreased during the pandemic. The number of SAH and TBI patients treated during the pandemic was significantly lower in March 2020 than December 2019, although indications for emergency treatment of neurosurgical patients have remained similar and guidelines specifically state that neurosurgical emergencies need to be handled according to already accepted knowledge and experience $[5,11,22,24]$. Only three centers stated that they would not admit one hypothetical typical neurosurgical SAH patient in need of intensive care. Several authors have described a decrease in trauma, probably secondary to lockdown and decreased travel [12], which agrees with fewer TBI patients in intensive care in March 2020. A similar finding was evident for SAH patients, but the difference was smaller. It has been suggested that SAH incidences have decreased also and the incidence of SAH may be prone to chance or seasonal flux. However, it is also possible that patients avoid medical consultations during the pandemic or get misdiagnosed because of confirmation biased healthcare workers suspecting Covid-19 in patients suffering from headaches, as suggested recently [25].

The obvious default response to decreased resources was to prioritize patients who would risk death or permanent loss of function unless treated and postpone care that could wait. Accordingly, most centers reported fewer elective craniotomies and increased time on the waitlist before surgery. Interestingly, a hypothetical patient with glioblastoma had an unchanged or shortened expected time to surgery in 15 centers and a doubled time in four. Hypothetical patients with meningiomas or cervical spinal stenosis were treated with a similar timeframe in six and seven centers, respectively, while waitlist would be increased with a few weeks in three and four and postponed until "after corona" in eleven and ten. Postponing care implies that the patients will still be treated and would not risk permanent deficits from the extended wait. One might even speculate that patients scheduled for meningioma or cervical stenosis surgery might experience decrease or stabilization of symptoms that may change the original surgical indication and reverse the decision to operate. Conservative management has a place for slowly growing meningiomas and cervical pathology $[18,26]$, and even surgeons probably operate a higher number of patients than theoretically necessary to avoid harm from the progressive disease. It is not possible to make an exact prognosis of which patients benefit from any treatment, and healthcare statistics typically deals with "number needed to treat" (NNT) as a measurement of how many patients must be treated for one to have the intended benefit. In pharmacological management, NNTs may be higher than 100 [27], while surgical therapies require values much closer to one; yet, the ideal of $\mathrm{NNT}=1$ is probably impossible to reach. It is probable that longer waitlist may force NNT closer to 1, if patients are followed closely and operated rapidly if their conditions deteriorate.

Under conditions like a pandemic, resource constraints may ensue and health services must be provided with attention to cost efficiency and inevitable priority settings. All prioritization decisions bring controversy [21, 28]. "Prioritization" and "triaging" suggest that patients will receive adequate treatment and do not necessarily risk harm from waiting or triaging to a certain treatment (Mathiesen T., submitted). Practically prioritization assesses the severity of untoward consequences and necessary urgency to treatment to avoid harm [4]. Notably, the algorithm entails the possibility that postponed care can lead to irreversible loss of function or even death. "Prioritization" under such conditions is no longer compatible with everybody getting access to legitimate care. It is more correct to use the term "rationing," which explicitly clarifies that treatment is not offered to everyone with a legitimate need. Extensively postponed treatment until "post-corona" may prove to be a form of disguised rationing. Rationing was more transparent when centers reported changed indications for surgery and intensive care between the December and March weeks. Elective craniotomies would not be offered to our hypothetical patients with glioblastoma or meningioma in six centers, and five would not treat the elective patient with spinal stenosis. It is likely that inability to offer surgery to the hypothetical GBM patient in or questionnaire would be an example of rationing that actually shortened the expected survival of the patient, since surgery postponed for several months would no longer be a relevant treatment option. The 
centers that modified surgical indications for elective surgery also reported restricted admission for the hypothetical emergency patients. One might argue that surgery of a meningioma or spinal stenosis would be undertaken after corona restrictions were reversed, but not offering surgery to a GBM patient or patients with the urgent conditions ICH and SAH clearly constitutes rationing of care. In summary, some form of rationing via changed surgical indications was evident in ten of the 25 responding centers $(40 \%)$. Rationing was clearly implemented to adjust to Covid-19. The ten centers that reported changed indications for surgery also stated that not all patients could get treatment according to legitimate needs.

\section{Immediate changes of neurosurgical services in response to the pandemic}

It appears that the immediate response in all centers was to postpone non-urgent care and to reconsider indications for patients in higher age groups or with severe conditions where benefit from neurosurgical treatment was uncertain, such as elderly patients with intracerebral hematoma or comatose patients with SAH. These measures were also typically recommended in guidelines and other articles, although publications became available when measures already were taken $[5,6$, 11]. European neurosurgeons largely lack specific training, knowledge, or experience of practice during a pandemic, but acted similarly and it appears effectively, since only marginal changes appear to have affected the long-term prospects of most neurosurgical patients. This observation illustrates a human faculty to practically use available knowledge and solve a new unexpected problem. Moreover, guidelines gave only general recommendations and left interpretation and application to local medical experts. The post hoc publication of guidelines may seem ironical or useless, but we argue that the publications filled a need; they reflected extensive consensus and might serve as retrospective confirmation that the challenge was met appropriately and in agreement with peers. Still, our survey indicated that application varied extensively. It may well be affected by differences in severity of the pandemic, but we also found major differences in neurosurgical capacity per catchment population, catchment area of individual centers, and neurosurgical culture.

\section{Collateral damage}

The term "collateral damage" describes untoward effects on health that were indirectly caused by SARS-CoV-2 [14], which may have taken several forms related to resource shortage, misdiagnoses, and reluctance to fill available hospital beds.

It is obvious that deviation of healthcare resources to a new entity deprives existing therapies, at least during an adjustment phase. It is obvious from our questionnaire that neurosurgical care has been rationed and patients have been deprived of neurosurgical care because of lacking resources and redistribution of resources. The most obvious shift was maybe that ventilators and anesthesiology staff were shifted from neurosurgical care to lifesaving Covid-19 therapy.

Many countries in Europe became prepared in advance because they had realized what had happened in unexpectedly hit, unprepared Italy. Many centers in countries that were not severely hit by Covid-19 decreased their elective activity and restricted indications for surgery very rapidly, while their capacity remained comparable with centers with extensive Covid-19 loads. The response reflected a principle of precaution, since lack of preparation for the pandemic would have been negligent if the pandemic would have reached the specific region. A draconic shutdown of "non-emergency" treatment also in centers with a small load of Covid-19 was probably rational but might have unnecessarily deprived patients of neurosurgical care. Still, it is probable that the dichotomization between urgent and non-urgent care failed to handle patients with intermediate needs and may even have emphasized "urgency" over "benefit." Our hypothetical 75-year-old patient with ICH may have had a very urgent condition with limited benefit of surgery, while a less debilitating elective condition in our hypothetical elective patients may have had more to lose with extensively postponed surgery. Sufficient empirical data on postponed "non-urgent" surgery is not available, and the sudden need to prioritize has identified an important topic to survey - also to critically analyze practices in centers that already had institutionalized long waitlists prior to the pandemic.

The coronavirus can induce neurological disorders such as polyneuropathy, encephalopathy, and demyelinating lesions [29]. Headache, disturbance of consciousness, olfactory nerve dysfunction, and seizures have been reported among the symptoms of the disease. Subsequently, there is evidence of misdiagnoses when non-Covid-19-related symptoms of neurosurgical disease were mistakenly evaluated as Covid-19 symptoms, leading to patient's and doctor's delay [15, 25]. Patients and physicians may have been reluctant to occupy hospital beds for fear of getting infected by SARS-CoV-2 [17]. Likewise, it was important to ensure that neurosurgical wards and the operating room were maintained free from Covid-19. This requires continuous active surveillance and testing [30].

Moreover, we have pushed a dual burden ahead. Many patients had their treatment postponed for months: it will become necessary to treat these patients while new patients get diagnosed and the total number of patients needing care has accumulates. The other burden is the healthcare economical debt. The financial resources were stretched by collapsing income and failing economy, while healthcare spending to save lives increased. 


\section{Differences between centers and neurosurgical culture}

The burden of Covid-19 differed between European countries. The fact that pandemics' burden of death varies from country to country is well known [20]. Five participating centers considered that all patients with legitimate medical needs received care as needed in December 2019 and March 2020, while fifteen centers could no longer meet all medical needs in March 2020, and five centers reported that some patients were left with unmet legitimate needs already in December 2019. Still, four centers apparently continued business as usual although some had considerable numbers of Covid-19 patients in the country.

As expected, our figures indicate that centers were worst affected if their regions were severely hit and if their pre hoc resources were comparatively low. In fact, some centers had fewer beds and longer waitlist even before the pandemic than those others had during Covid-19 measures. Thus, small margins forced changes in indications and services to a high extent. It was also evident that the centers with comparatively low resources/million inhabitants stated doubts whether legitimate needs were met already before this pandemic.

Another issue is cultural difference of indications. Some centers did not consider any of the three hypothetical patients with intracerebral hematomas as surgical candidates. The observation may reflect a quest for evidence of benefit from prospective randomized trials, while others may have used evidence based on other literature and experiences. One issue to explore is whether the limitations in indications reflect adaptation to limited resources or whether resources have been limited secondary to decreased demand. The ethics of extrapolating results from the negative prospective randomized trials [19] with questionable external validity [13] merit separate studies. It is important to survey whether a relative lack of resources might have influenced the readiness to accept trial outcomes as evidence for non-neurosurgical management of intracerebral hemorrhage.

It appears that most centers and countries, even among those hit worst, have been able to deliver extensive neurosurgical services so that emergency surgery has only been limited in few centers, while most centers have postponed surgery of non-urgent character. Thus, a backlog has been created, and the impact of this backlog may also differ depending on available resources $[2,16]$. It is probable that large numbers of available beds will create less morbidity from extended waitlists than already limited resources. Taken together, our analyses indicate that resources in terms of available neurosurgical beds vary extensively in Europe. Centers with large margins have responded very effectively, and centers with small margins appeared to have provided cost-effective services before the pandemic but have upheld services only if their regions were hit mildly by Covid-19. In this context, the lack of consensus on a "constant need to prioritize healthcare" needs to be studied further. Several of the seemingly most affluent countries had few neurosurgical beds, reported an ongoing discourse on prioritization, and restricted services and indications to a higher extent than centers that did not report a discourse of prioritization. It is possible that the discourse of prioritization rapidly had focused on how to prioritize and decrease healthcare spending rather than to discuss which rationing is necessary and acceptable. The idea that prioritization of healthcare in the sense of "rationing" is maybe not necessary might need further exploration in the future.

Taken together, there was no unifying feature for the centers that maintained services. The majority was situated in areas with limited Covid-19 burden and none had very few beds per population. A family likeness might be a combination of sufficient numbers of beds, which would be higher in the regions struck hardest, and work ethics where all patients were considered to be entitled to having legitimate medical needs met.

\section{Limitations}

Our survey is entirely dependent on reports from the responding neurosurgeons and selected centers; we had a short timeframe to receive responses and may have failed to get relevant input. The responses from each center are representative for the centers but may not necessarily reflect larger regions, countries, or Europe, although they provide a snapshot from different areas with different healthcare systems and SARS-CoV-2 exposures. Even during the course of the pandemic in a particular department, patient management policy could have changed more or less. This is why we use the term "snapshot" when we are examining a rapidly changing situation. Quantitative data on sizes of catchment areas and available beds agreed well internally within reports from each center, but such data may be differently defined in different healthcare systems. Strictly regionalized large centers in Nordic countries have very strictly defined populations to serve, while smaller neurosurgical centers in densely populated areas may have an overlap of catchment areas with other hospitals. Moreover, the normalization of data from 1 week in departments of different sizes is prone to flux and possible disproportionate influence from chance fluctuations in centers with small catchment areas, since their reported figures were multiplied while figures from the largest centers were divided.

Moreover, the assessment of medical needs is subjective and value laden. Assessment of surgical indications may vary between individual surgeons. We attempted to maximize reproducibility and representability by inviting five senior surgeons to fill out the questionnaires from each center and thereby compensate for individual idiosyncrasy and thereby estimate that the responses do represent local consensus. 
We compared 1 week in December with 1 week in March. One can question whether a week during March in a different year without a pandemic would have been a better control. The choice of December was made to allow for the detection of the probable sudden sharp change in the care of neurosurgical patients because of the pandemic, which we considered would be better reflected with comparison with a week close in time. Moreover, one can question which measure of Covid19 burden would best reflect an impact on practice. Practice is affected by a combination of expectations and need to react to a real situation, while corona statistics reflect disease spread and need for intensive care with a delay. The number of Covid-19 reflected deaths can reflect several weeks of intensive care utilization, and Sars-CoV-2 can be transmitted several weeks before infection is diagnosed. Moreover, there is a delay before cases appear in statistics and country statistics fail to reflect regional differences. For these reasons, any surrogate parameter of Covid-19 burden is diffuse. We chose population-adjusted national values of diagnosed cases and Covid-19-related deaths as a cumulative approximation of the perceived and actual pandemic challenges during the surveyed pandemic week.

\section{Conclusions}

We have conducted a rapid survey of changes of neurosurgical care during the Covid-19 pandemic. Rationing of neurosurgical care was common and neurosurgical activity was decreased in $80 \%$ of responding centers. Yet, differences were unexpectedly large in available resources and adaption to the pandemic. We need to further survey how attitudes to neurosurgical care in different series affect our populations and which margins of resources might be needed to provide neurosurgical care according to professional ethics.

\section{Compliance with ethical standards}

Conflict of interest The authors declare that they have no conflict of interest.

Ethical approval All procedures performed were in accordance with the ethical standards of the institutional and national research committee (Swedish Ethical Review Authority) and with the 1964 Helsinki declaration and its later amendments. For this type of study, a questionnaire survey, formal consent is not required. Yet, informed consent was obtained from all individual responders to the questionnaire.

\section{References}

1. Dobran M, Paracino R, Iacoangeli M (2020) Letter to the editor by Dobran Mauro, Paracino Riccardo, and Iacoangeli Maurizio regarding "Neurosurgery during the COVID-19 pandemic: update from Lombardy, northern Italy." Zoia C, Bongetta D, Veiceschi P,
Cenzato M, Di Meco F, Locatelli D, Boeris D, Fontanella MM. Acta Neurochir (Wien). 2020 Mar 28. 10.1007/s00701-02004305-w. Acta Neurochir 162(6):1223-1224. https://doi.org/10. 1007/s00701-020-04332-7

2. Galarza, M., \& Gazzeri, R. (2020). Letter: collateral pandemic in face of the present COVID-19 pandemic: a neurosurgical perspective. Neurosurgery. https://doi.org/10.1093/neuros/nyaa155

3. Hulsbergen AFC, Eijkholt MM, Balak N, Brennum J, Bolger C, Bohrer AM, Feldman Z, Holsgrove D, Kitchen N, Mathiesen TI, Moojen WA, Sampron N, Sames M, Sandvik U, Tisell M, Broekman MLD (2020) Ethical triage during the COVID-19 pandemic: a toolkit for neurosurgical resource allocation. Acta Neurochir 16:1-6. https://doi.org/10.1007/s00701-020-04375-w

4. Jean WC, Ironside NT, Sack KD, Felbaum DR, Syed HR (2020) The impact of COVID-19 on neurosurgeons and the strategy for triaging non-emergent operations: a global neurosurgery study. Acta Neurochir 162(6):1229-1240. https://doi.org/10.1007/ s00701-020-04342-5

5. Zoia C, Bongetta D, Veiceschi P, Cenzato M, Di Meco F, Locatelli D, Boeris D, Fontanella MM (2020) Neurosurgery during the COVID-19 pandemic: update from Lombardy, northern Italy. Acta Neurochir 162(6):1221-1222. https://doi.org/10.1007/ s00701-020-04305-w

6. Bernucci C, Brembilla C, Veiceschi P (2020) Effects of the COVID-19 outbreak in Northern Italy: perspectives from the Bergamo Neurosurgery Department. World Neurosurg 137:465468.e1. https://doi.org/10.1016/j.wneu.2020.03.179

7. Borsa S, Bertani G, Pluderi M, Locatelli M (2020) Our darkest hours (being neurosurgeons during the COVID-19 war). Acta Neurochir 162(6):1227-1228. https://doi.org/10.1007/s00701020-04333-6

8. Ganau M, Netuka D, Broekman M, Zoia C, Tsianaka E, Schwake M, Balak N, Sekhar A, Ridwan S, Clusmann H, EANS IM Committee (2020) Neurosurgeons and the fight with COVID-19: a position statement from the EANS Individual Membership Committee [published online ahead of print, 2020 May 29]. Acta Neurochir 2020:1-6

9. Schaller K (2020) Neurosurgeons in the Corona crisis: striving for remedy and redemption. A message from the president of the EANS. Acta Neurochir 162(6):1217-1219. https://doi.org/10. 1007/s00701-020-04306-9

10. Worldometer report: Death rate/country. (2020) Retrieved 20200519, 2020, from https:/www.worldometers.info/ coronavirus/?utm_campaign=homeAdvegas 1 ?\%22 (accessed 20200519)

11. Castelnuovo P, Turri-Zanoni M, Karligkiotis A, Battaglia P, Pozzi F, Locatelli D (2020) Italian Skull Base Society Board, Italian Skull Base Society Board (Società Italiana Basicranio [SIB]), Bernucci C, Iacoangeli M, Krengli M, Marchetti M, Pareschi R, Pompucci A, Rabbiosi D. Skull-base surgery during the COVID-19 pandemic: the Italian Skull Base Society recommendations. Int Forum Allergy Rhinol

12. Christey G, Amey J, Campbell A, Smith A (2020) Variation in volumes and characteristics of trauma patients admitted to a level one trauma centre during national level 4 lockdown for COVID-19 in New Zealand. N Z Med J 133(1513):81-88

13. de Oliveira Manoel AL (2020) Surgery for spontaneous intracerebral hemorrhage. Crit Care 24(1):45. https://doi.org/10.1186/ s13054-020-2749-2

14. Feral-Pierssens A, Claret P, Chouihed, T. Collateral damage of the COVID-19 outbreak. Eur J Emerg Med April 27, 2020 - Volume Publish Ahead of Print - Issue - https://doi.org/10.1097/MEJ. 0000000000000717

15. Gandia-Gonzalez ML, Saez-Alegre M, Roda JM (2020) Neurosurgeons on the frontline of COVID-19: no place for 
surgery? Acta Neurochir. https://doi.org/10.1007/s00701-02004390-x

16. Giussani C, Sganzerla E, Valvassori L, Alparone M, Citerio G (2020) The response during a pandemic is a blurred vision of the future. Reflections on the Lombardy reorganization of the neurosurgical emergencies during the COVID-19. Acta Neurochir 162(6):1225-1226. https://doi.org/10.1007/s00701-020-04327-4

17. Hostiuc S, Molnar AJ, Moldoveanu A, Aluas M, Moldoveanu F, Bocicor I, Dascalu MI, Badila E, Hostiuc M, Negoi I (2018) Patient autonomy and disclosure of material information about hospitalacquired infections. Infect Drug Resist 11:369-375. https://doi. org/10.2147/IDR.S149590

18. Hug A, Hahnel S, Weidner N (2018) Diagnostics and conservative treatment of cervical and lumbar spinal stenosis. Nervenarzt 89(6): 620-631. https://doi.org/10.1007/s00115-018-0516-2

19. Mendelow AD, Gregson BA, Fernandes HM, Murray GD, Teasdale GM, Hope DT, Karimi A, Shaw MD, Barer DH, investigators S (2005) Early surgery versus initial conservative treatment in patients with spontaneous supratentorial intracerebral haematomas in the International Surgical Trial in Intracerebral Haemorrhage (STICH): a randomised trial. Lancet 365(9457): 387-397. https://doi.org/10.1016/S0140-6736(05)17826-X

20. Morales KF, Paget J, Spreeuwenberg P (2017) Possible explanations for why some countries were harder hit by the pandemic influenza virus in 2009 - a global mortality impact modeling study. BMC Infect Dis 17(1):642. https://doi.org/10.1186/s12879-0172730-0

21. Norheim OF (2016) Ethical priority setting for universal health coverage: challenges in deciding upon fair distribution of health services. BMC Med 14:75. https://doi.org/10.1186/s12916-0160624-4

22. Ramakrishna R, Zadeh G, Sheehan JP, Aghi MK (2020) Inpatient and outpatient case prioritization for patients with neuro-oncologic disease amid the COVID-19 pandemic: general guidance for neurooncology practitioners from the AANS/CNS Tumor Section and Society for Neuro-Oncology. J Neuro-Oncol 9:1-5. https://doi. org/10.1007/s11060-020-03488-7

23. Robertson FC, Esene IN, Kolias AG, Khan T, Rosseau G, Gormley WB, Park KB, MLD B, Global Neurosurgery Survey Collaborators (2019) Global perspectives on task shifting and task sharing in neurosurgery. World Neurosurg X 6:100060. Published 2019 Sep 9. https://doi.org/10.1016/j.wnsx.2019.100060

24. Bernhardt D, Wick W, Weiss SE, Sahgal A, Lo SS, Suh JH, Chang EL, Foote M, Perry J, Meyer B, Vajkoczy P, Wen PY, Straube C, Pigorsch S, Wilkens JJ, Combs SE (2020) Neuro-oncology management during the COVID-19 pandemic with a focus on WHO grade III and IV gliomas. Neuro Oncology 5:noaa113. https://doi. org/10.1093/neuonc/noaa113

25. Tartara F, Cofano F, Zenga F, Boeris D, Garbossa D, Cenzato M (2020) Are we forgetting non-COVID-19-related diseases during lockdown? Acta Neurochir. https://doi.org/10.1007/s00701-02004385-8

26. Black PM (1995) Benign brain tumors. Meningiomas, pituitary tumors, and acoustic neuromas. Neurol Clin 13(4):927-952
27. Scott IA, Hilmer SN, Reeve E, Potter K, Le Couteur D, Rigby D, Gnjidic D, Del Mar CB, Roughead EE, Page A, Jansen J, Martin JH (2015) Reducing inappropriate polypharmacy: the process of deprescribing. JAMA Intern Med 175(5):827-834. https://doi.org/ 10.1001/jamainternmed.2015.0324

28. Balak N, Broekman MLD, Mathiesen T (2020) Ethics in contemporary health care management and medical education. J Eval Clin Pract 26(3):699-706. https://doi.org/10.1111/jep.13352

29. Zanin L, Saraceno G, Panciani PP, Renisi G, Signorini L, Migliorati K, Fontanella MM (2020) SARS-CoV-2 can induce brain and spine demyelinating lesions. Acta Neurochir 4:1-4. https://doi.org/10. 1007/s00701-020-04374-x

30. Rustemi O, Segna A, Zanusso M, Volpin L, Raneri F (2020) Covid19 diffusion in a neurosurgical "clean" department: the asymptomatic Trojan horse. Acta Neurochir. https://doi.org/10.1007/s00701020-04386-7

Comments The authors are to be commended for designing and achieving this timely due "snapshot."

The rationale for constructing the questionnaire and the interpretation of the responses obtained are certainly sound, as well as the interpretation of the results in the light of well-known differences in the health systems existing in Europe.

The limitation of this survey mainly consists on its dependency on the limited number of interviewed centers. The authors therefore recognize that the data presented may not reflect larger regions or countries. We would like to emphasize one more aspect peculiar to the COVID-19 pandemic: its propensity to hit in a patchy way. Concerning Italy, not only neurosurgical centers located in the center or south parts of the country were relatively unaffected, but also centers located few dozens of kilometers from others heavily suffering could keep going usual standards of activity. For example, neurosurgical cases treated in Padova on March to May 2020 were comparable in numbers and typology to the previous years, with the only exception that traffic-related injuries virtually disappeared.

It is clear that many aspects of the epidemiology of the pandemic are still to be understood, and this may underlie otherwise inexplicable locoregional differences.

This work is a valuable piece of clinical research, important for Health Administrators in the undesired eventuality of a new wave of the disease. Domenico d'Avella,

Franco Chioffi

Padova, Italy

Publisher's note Springer Nature remains neutral with regard to jurisdictional claims in published maps and institutional affiliations. 


\section{Affiliations}

T. Mathiesen ${ }^{1,2,3}$ (D) M. Arraez ${ }^{4} \cdot$ T. Asser ${ }^{5} \cdot$ N. Balak $^{6} \cdot$ S. Barazi ${ }^{7}$ - C. Bernucci ${ }^{8} \cdot$ C. Bolger ${ }^{9}$ - M. L. D. Broekman ${ }^{10,11}$. A. K. Demetriades ${ }^{12} \cdot$ Z. Feldman ${ }^{13} \cdot$ M. M. Fontanella ${ }^{14} \cdot$ N. Foroglou ${ }^{15} \cdot$ J. Lafuente $^{16} \cdot$ A. D. Maier ${ }^{1,2} \cdot$ B. Meyer ${ }^{17}$. $^{13}$

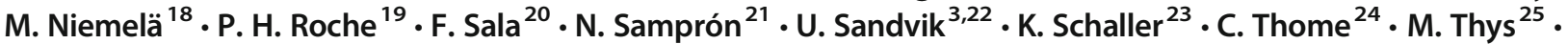
M. Tisell ${ }^{26} \cdot$ P. Vajkoczy ${ }^{27} \cdot$ M. Visocchi ${ }^{28}$ - on behalf of the EANS Ethico-legal committee

1 Department of Neurosurgery, Rigshospitalet, Blegdamsvej 9, 2100 Copenhagen, Denmark

2 Department of Clinical Medicine, University of Copenhagen, Copenhagen, Denmark

3 Department of Clinical Neuroscience, Karolinska Institutet, Stockholm, Sweden

4 Department of Neurosurgery, Carlos Haya University Hospital, University of Malaga, Malaga, Spain

5 University of Tartu, Tartu, Estonia

6 Department of Neurosurgery, Istanbul Medeniyet University, Göztepe Education and Research Hospital, Istanbul, Turkey

7 King's College Hospital, London, UK

8 Department of Neuroscience and Surgery of the Nervous System, ASST Papa Giovanni XXIII Hospital, Bergamo, Italy

9 National Centre for Neurosurgery, Beaumont Hospital, Dublin, Ireland

10 Departments of Neurosurgery, Haaglanden Medical Center and Leiden University Medical Center, Leiden University, Leiden, Zuid-Holland, the Netherlands

11 Department of Neurology, Massachusetts General Hospital, Boston, MA, USA

12 Department of Neurosurgery, Western General Hospital, Edinburgh, UK

13 Department of Neurosurgery, Sheba Medical Center, Ramat Gan, Israel

14 Neurosurgery, Department of Medical and Surgical Specialties, Radiological Sciences and Public Health, University of Brescia, Spedali Civili di Brescia, Brescia, Italy
15 Department of Neurosurgery, Aristotle University of Thessaloniki, AHEPA University Hospital, Thessaloniki, Greece

16 Neurosurgery, Hospital Del Mar, Barcelona, Spain

17 Department of Neurosurgery, Technical University of Munich, Klinikum rechts der Isar, Munich, Germany

18 Helsinki University and Helsinki University Hospital, Helsinki, Finland

19 Department of Neurosurgery, Hôpital Nord, Assistance Publique Hôpitaux de Marseille, Aix Marseille Université, Marseille, France

20 Section of Neurosurgery, Department of Neurosciences, Biomedicine and Movement Sciences, University Hospital, Verona, Italy

21 Servicio de Neurocirugía, Hospital Universitario Donostia, San Sebastián, Spain

22 Department of Neurosurgery, Karolinska University Hospital, Solna, Sweden

23 Department of Neurosurgery, Geneva University Medical Center \& Faculty of Medicine, Geneva, Switzerland

24 Department of Neurosurgery, Medical University Innsbruck, Innsbruck, Austria

25 Neurosciences Department, Grand Hopital de Charleroi, Charleroi, Belgium

26 Department of Neurosurgery, Institute of Neuroscience and Physiology, Sahlgrenska University Hospital, Göteborg, Sweden

27 Department of Neurosurgery, Charite Universitätsmedizin Berlin, Berlin, Germany

28 Department of Neurosurgery, Fondazione Policlinico Universitario Agostino Gemelli, Rome, Italy 